\title{
Air quality action planning: barriers to remediation in local air quality management
}

\author{
J. H. Barnes, E. T. Hayes \& J. W. S. Longhurst \\ Air Quality Management Resource Centre, \\ University of the West of England, Bristol, UK
}

\begin{abstract}
This paper explores the operation of air quality action planning within the framework of UK air quality management with particular reference to the key actors and actions. The paper examines the intentions of action planning policy and reflects on the role of local government in achieving these intentions. A review of primary sources and peer-reviewed literature identifies some of the barriers to action plan implementation and explores why these barriers remain in place after more than a decade of action. As a nationally mandated but locally operated policy, it is argued that there is a mismatch between ambition, powers and effects. The paper concludes with an exploration of the opportunities to reconceptualise and re-energise the air quality action planning process in order to provide appropriate protection for public health.
\end{abstract}

Keywords: local air quality management, action plans, $\mathrm{NO}_{2}$, local authorities.

\section{Introduction}

Over the last 60 years the nature of air pollution in the UK has changed considerably in terms of its sources, its visibility and its management; though parallels can be drawn between then and now. The fatal Great Smogs of London and Manchester in the 1950s and early ' 60 s were as a result of widespread urban industrial and domestic particulate emissions from coal-burning. The Clean Air Acts (1956 and 1968) gave local authorities the responsibility to declare Smoke Control Areas and legislated against the use of non-compliant fuels and appliances in domestic properties within these areas. Facilitated by coincident improvements in general living standards resulting from increased personal wealth and a widespread shift to natural gas for domestic heating and cooking, 
the legislation resulted in a dramatic improvement in visible air pollution [1]. The subsequent exponential growth in vehicle use, however, has led to a much more intransigent, invisible air pollution scenario with complex gaseous emissions chemistry, requiring similarly complex solutions. Legislation, through the Environment Act (1995) (Part IV), again gave responsibility to local authorities to declare Air Quality Management Areas (AQMAs) and implement local Air Quality Action Plans (AQAPs). The EU Directive on ambient air quality assessment and management (96/62/EC) was adopted after the Environment Act 1995 and action in response was reserved for central government with particular emphasis placed upon improvements in fuel quality and engine technology. However the pace of technological improvement is slow and the continual increase in vehicle usage is undermining efforts at all levels to reduce traffic-related air pollution.

\subsection{Local air quality management}

The first national Air Quality Regulations, which was published as a requirement of the 1995 Environment Act in December 1997, established health-based objectives for eight air pollutants (benzene, 1,3-butadiene, carbon monoxide, lead, nitrogen dioxide, ozone, particulates $\left(\mathrm{PM}_{10}\right)$ and sulphur dioxide) [2]. These objectives anticipated the Limit Values prescribed in the European Air Quality Framework Directive $(96 / 62 / \mathrm{EC})$ and subsequent daughter Directives (1999/30/EC, 2000/69/EC, 2002/3/EC), and the national Air Quality Strategy set out the government's approach to meeting them [3]. According to the Strategy the government's responsibility was to create a framework for managing air quality for others to implement. Responsibility for improving air quality fell to local authorities, private industry and the Environment Agency, as regulators, and local government with responsibility for small-scale industry, local transport and planning [4]. The principle behind this subsidiarity approach is that sources are best managed at the lowest administrative level to ensure resources are efficiently and proportionately targeted taking account of local conditions; "Action should be taken to improve air quality at the most appropriate level, be it international, European, national or local" [3]. At the time of the initial Strategy the government did not foresee how intractable and widespread the problem of traffic pollution would become. The 1997 Air Quality Strategy stated that universally applied policies should be sufficient to achieve the air quality objectives for most of the country and that the role of Local Air Quality Management (LAQM) should be in supplementing and "fine tuning" central policies at local hotspots where national measures would be too blunt or expensive [3]. The Strategy predicted that emissions and fuel quality standards would almost achieve the lower threshold of the estimated 48-62\% NOx emissions reductions required to meet the 2005 objective deadline, but that more stringent standards, and a reliance on local measures, would be required to prevent a renewed increase in emissions resulting from the predicted growth in vehicle use post-2010. Although the predicted post-2010 growth in UK vehicle use has stalled [5], it is apparent that national policies have not achieved as much 
as predicted, placing an increased onus on local authorities' AQAPs to improve air quality.

\subsection{Local air quality action planning}

The 1997 Air Quality Regulations set health-based air quality objectives that local authorities were to work towards achieving by $31^{\text {st }}$ December 2005 . Failure to meet these objectives by the deadline required local authorities to declare, as a minimum, the area(s) of exceedence as an AQMA and to prepare an AQAP to work "in pursuit of" achieving them [3]. Air quality action planning is the means by which local authorities in the UK are required by central government to set out their intentions for working towards meeting national air quality objectives.

In the absence of clear government action planning advice at the start of the process, non-statutory guidance was published by the then National Society for Clean Air and the Environment (NSCA), providing practical ideas and methodologies for constructing AQAPs [6,7]. This guidance suggested that AQAPs should focus on the pollution source, as identified in the Further Assessment report, and measures should be prioritised for implementation according to their cost effectiveness, predicted air quality improvement, non-air quality impacts, stakeholder perception and the practicability of their implementation. Consultation and steering groups were advocated from the outset to gain support from the public, politicians, local commercial interests and participants who would be key players in the implementation of measures. Suggested traffic measures ranged from Compulsory Purchase Orders, Low Emission Zones (LEZs) and traffic management schemes, to Green Travel Plans and Bus Quality Partnerships. County-level authorities are required by the Department for Transport to produce five-yearly Local Transport Plans (LTP) which set out proposed schemes to improve local traffic, and, where appropriate, local authorities (in England) can integrate their AQAP with the LTP to facilitate implementation.

The government manages local air quality action planning via contracted consultants, who are periodically commissioned to assess progress on the AQAP process. Two assessment reports have been published, in 2004 [8] and 2007 [9], on behalf of Defra. In addition the government also commissioned its in-house consultants to carry out a review of the LAQM process which was published in 2010 [10], and for which the authors of this paper were commissioned to undertake a questionnaire survey of local authorities [11]. The analysis and outcomes of these reports allowed the government to maintain oversight of the number of AQAPs submitted for consultation and to identify any systematic or specific policy or implementation issues.

The first AQAPs were submitted in 1999/2000 and now some $60 \%$ of local authorities have declared an AQMA, primarily for traffic-related pollutants $\left(\mathrm{NO}_{2}\right.$ and $\mathrm{PM}_{10}$ ). Despite the preparation of over 400 draft and final AQAPs over the last decade, no traffic-related AQMAs have been revoked solely on the basis of AQAP implementation. This paper explores some of the difficulties experienced by those seeking to devise and implement AQAPs for traffic-related AQMAs, 
and questions whether local government is the most appropriate administrative level to manage traffic-related air pollution.

\section{Method}

This paper utilises primary sources and peer-reviewed literature to identify the successes and barriers to AQAP implementation. The primary sources are the local authority responses that were received for the review of LAQM questionnaire survey, undertaken by AQMRC, UWE $[10,11]$. The questionnaire was sent to all UK local authorities and achieved a 55\% response rate. The questions covered all aspects of LAQM with specific sections focusing on the various elements, including AQAPs. The responses were analysed into parent and sub-themes using Grounded Theory methodology, which ensures that the data generated is used as evidence for theory construction rather than evidence of a pre-existing theoretical position. These responses were summarised and published as part of a government-funded review of LAQM [10] and are also available in full online (http://uk-air.defra.gov.uk/news?view=129) [11]. Evidence is drawn from two reviews of air quality action planning [8, 9], and the House of Commons Environmental Audit Committee reports on air quality $[12,13]$.

\section{Barriers to action plan implementation}

\subsection{Criticisms of air quality action planning}

The 2010 review noted that, in contrast to the structured reporting mechanism of the diagnostic Review and Assessment process, "...the action planning and delivery elements of LAQM are not thought to be working well" [10]. The questionnaire conducted as part of the LAQM review revealed that $85 \%$ (202) respondents surveyed considered that limited powers and engagement with other agendas undermined the LAQM process, with 7\% (17) explicitly highlighting action planning as a weakness [11]. Drawing on the evidence of the questionnaire survey and discussions with stakeholders in air quality policy, the review concluded that there was "insufficient political and public support", a necessary "reliance on other departments and agencies", and "inadequate powers or resources" for action planning to deliver air quality improvements (Figure 1). These same key points had been raised by local authorities in the earlier reviews $[8,9]$ and yet apparently remained unresolved.

The 2010 review also suggested that the burden of responsibility for reducing air pollutants may be misplaced, suggesting that a stronger lead from central government was required to reassess the contribution that local government could reasonably be expected to make. Also noted was a requirement for prescriptive guidance to allow authorities to implement those measures that are considered to be within their scope. This was a strongly held view with $23 \%$ (56) respondents stating that the AQAP process could be improved by more 


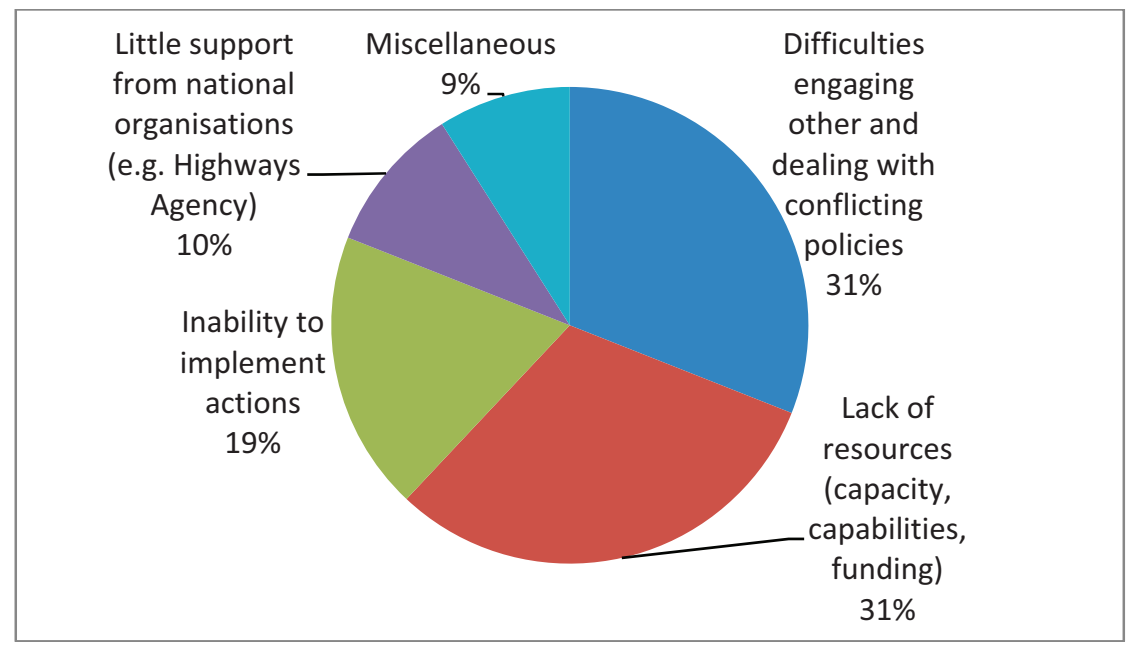

Figure 1: "What have been the main factors that have constrained the development of your air quality action plan?" [11].

national support and direction [11]. One point that was not specifically raised in the LAQM review, but which was highlighted by respondents to the questionnaire survey, was "[t]he mismatch between work of the UK government, submissions to the EU and the work in LAQM" [11]. This is a key point and one that, though linked to the previous one, is distinct as the political weight given to air quality management in local authorities can be crucially undermined by the relative importance conveyed by national government. These potential contributory factors, which are discussed below, can be distilled into four key areas:

- Funding/resources

- District level local authority powers

- Intra governmental co-operation

- Inter governmental co-ordination

\section{Discussion}

\subsection{Funding/ resources}

Defra have offered financial support to English local authorities since the LAQM programme began in 1997. This funding ( $\sim 2$ million p.a.) has been used to support monitoring and modelling and to diagnose air quality problems but is now targeted more specifically at implementing AQAP measures. In the last two years the government has reduced the local authority grants.

Local authorities are also able to obtain financial contributions towards specific AQAP measures from local developers by agreement under section 106 (s.106) of the Town and Country Planning Act 1990, Planning Policy Statement 
23. Local authorities can produce Supplementary Planning Documents (SPD) to prescribe the financial contribution required from new developments. Even with a SPD, it can be difficult to determine the cumulative effects of multiple developments, especially those that are submitted over a period of time, and to ensure that the s.106 contributions sought are equitable and sufficient. The risk of this strategy is, of course, that developers may choose to take their investment elsewhere, rather than pay a premium and face a potentially prolonged planning decision, and that air quality policy will have been seen to have limited economic development, which PPS 23 makes clear should not happen.

Local authorities with traffic-related AQMAs can obtain financial assistance from transport planners by linking their AQAPs with their county council's LTP, however, as with planning, this approach can have its own barriers in terms of departmental "silos" affecting communication and prioritisation of actions.

\subsection{District level local authority powers}

Local authorities are not legally obliged to achieve the national air quality objectives. They are, however, required to work towards meeting the objectives by drawing up AQAPs which set out the measures they intend to take in pursuit of them. The legislation was framed in this way because, in the government's view, it would be unreasonable to put a legal requirement on local authorities to achieve the objectives as so many of the sources of emissions are outside of their direct control. During the LAQM Review [10], and previous action planning evaluation surveys $[8,9]$, some local authorities and commentators suggested that this lack of judicial power has undermined the effectiveness of AQAPs and devalued LAQM. As local authorities do not have the means to implement all measures included in their AQAPs, some measures must be attributed to outside agencies. Engagement of these organisations with local authorities will be required for the latter to determine whether the measures have been implemented and to assess their likely impact. In many cases the impact of measures outside of their remit may be too complex for local authorities to be able to assess with any degree of accuracy [9]. This is particularly the case in considering measures to reduce traffic-related pollutants. Management of local roads is the responsibility of county or unitary authorities, and thus will require communication and cooperation from transport planners from within their own and neighbouring authorities, which in itself may be challenging [14, 15]. In addition the national road network of motorways and A-roads is managed by the Highways Agency for the Department for Transport (DfT), whose national transport policies ultimately govern the volume and quality of traffic on the roads [16].

\subsection{Intra governmental co-operation}

One of the main limitations to the effectiveness of AQAPs is the lack of liaison and commitment from internal departments and members. This is particularly the case for AQAPs that have been developed in conjunction with the LTP. Local authorities have reported that the transport agenda had already been set based on 
local political decisions and gave little scope for a single issue like air quality to influence the outcomes. Successful integration of an AQAP with an LTP relies heavily on a cooperative transport planning department and, in two-tier authorities, the coordination of district and county councils to integrate the plans, which in practice can prove problematic $[14,15]$. Typically obstacles have arisen through a lack of integrative guidance from central government, ineffective communication between environmental health and transport departments, differing timescales for AQAPs and LTPs, and low political priorities attributed to air quality measures in LTPs. Olowoporoku et al. [17] have suggested a conceptual model for managing traffic-related air pollution which seeks to address these issues through political, institutional and target integration supported by capacity and capability development for transport and environmental health officers, though the authors recognise the political will to achieve this is not currently apparent.

Similarly, ensuring that new developments do not hamper AQAP implementation requires a proactive local authority, a strong-willed environmental health officer and a cooperative planning department. Without a SPD, or similar process, in place, environmental health officers must screen all planning applications themselves or rely on their planning colleagues to flag up those applications that they deem likely to have significance for air quality management. This ad hoc approach can mean that developments likely to lead to a worsening of air quality, or that are likely to increase exposure in areas with already poor air quality, are missed and not adequately assessed.

Beattie [18] found that the majority of local authorities do not have the strategic managerial frameworks in place that are necessary to implement LAQM and, in particular, action planning effectively, and the LAQM review confirmed that this is still the case [10]. Insufficient time is allowed to develop frameworks to enable measures designed to improve air quality to be implemented effectively. Among Beattie's recommendations was a suggestion that local authorities should adopt a more corporate strategic approach to air quality management and change their focus from diagnosis of air quality problems to the implementation of 'solutions packages' [18].

\subsection{Inter governmental co-ordination}

The 2010 LAQM Review supported the need for cross-departmental cooperation, highlighting 'health', 'transport', 'land-use planning' and 'climate change' as the four policy areas most closely linked to air quality, but suggested that the lead for this should be national [10]. The House of Commons Environmental Audit Committee (EAC) also recognised the need for inter departmental co-operation at a national level $[12,13]$. The Department for Environment, Food and Rural Affairs (Defra) and the Department for Transport were, until the termination of Public Service Agreement 28, the only government departments with a remit for air quality. However, in both their 2010 and 2011 Air Quality reports the EAC MPs also strongly implicated the Department for Communities and Local Government, the Department of Health, the Department 
of Energy and Climate Change and the Treasury in contributing to air quality problems, and therefore having responsibility for their solutions [12, 13].

One of the confounding issues local authorities have faced in determining the measures to be included in AQAPs is the reliance on emission factors to predict future air quality. Until recently, local authorities were advised to use factors derived from the National Atmospheric Emissions Inventory (NAEI) to determine future year projections of roadside nitrogen dioxide. These factors indicated that concentrations were steadily declining, despite contradiction from monitoring data that suggested previously forecast reductions in $\mathrm{NO}_{2}$ concentrations using these factors had not materialised. The message from Defra that emissions reductions would improve air quality over the long-term may have led local authorities to deprioritise local action. Recent evidence, however, has suggested that the assumptions on which the NAEI, and therefore the emissions factors, was based were flawed, as the improvements in emissions which the newer Euro standard engines were predicted to deliver in laboratory trials were not being realised on the road [19]. In the absence of a clear alternative, Defra was slow to provide guidance and has now resorted to adopting the similarly limited European COPERT 4 emissions inventory. This leaves local authorities no clearer about the practicability of relying on emissions factors to assess new developments and signals no clear message on the importance of implementing local action plan measures.

There is, at present, a dual approach to air quality management in the UK. At a national level, Defra and the Devolved Administrations of Scotland, Wales and Northern Ireland are focused on meeting the EU Limit Values in their designated Zones and Agglomerations, based on concentrations measured by the national Automatic Urban and Rural Network (AURN) of monitors and modelling. At the same time, local authorities are working towards (not dissimilar) national air quality objectives for areas of exceedence, designated locally as AQMAs and identified through local air quality monitoring and modelling. The national and local designations are not related and national government do not report local monitoring concentrations or AQMAs to the European Commission. Many local authorities continue to exceed the air quality objectives for $\mathrm{NO}_{2}$ and $\mathrm{PM}_{10}$ whilst Defra is also failing to meet the EU Limit Values for the same pollutants. In September 2011 Defra submitted a Time Extension Notification (TEN) to the European Commission which set out Action Plans for each zone and agglomeration with measures to reduce concentrations of $\mathrm{NO}_{2}$. These Action Plans, for the first time, included AQAPs developed by local authorities and an explicit intention to promote the uptake of local LEZs, though no specific incentives or prioritisation strategy, have been forthcoming, with implementation ultimately left to local authorities' discretion [20].

\subsection{Why do barriers remain?}

\subsubsection{Flawed subsidiarity}

The principal barrier to successful implementation of AQAPs is a result of a flawed notion of subsidiarity. The optimum administrative level for the improvement of traffic-related local air quality does not appear to lie with local 
authorities. The primary source of the air quality problem in the UK, traffic, is beyond the control of local government but national government has done little to empower local authorities to help remediate the effects of traffic pollution.

LAQM could have been used to assist national government with achieving the European Air Quality Framework Directive, but the connection between the national and local approaches to reduce air pollution has lacked central coordination. Beyond issuing statutory guidance and providing limited funding, there has been no centralised facilitation of local measures to reduce air pollution. Rather there has been a continual drive to reduce the burden on local authorities by offering a light-touch approach to management, and latterly an almost complete devolution of responsibility through the introduction of the Localism Act 2011 [21]. This hands-off approach is unlikely to drive significant improvements in local air quality, which already competes unfavourably with other more apparent local issues.

\subsubsection{No Legal obligation}

Although the legislation and guidance on the requirement for submission of an AQAP within 18 months of declaration of an AQMA is clear, Defra are ineffectual when presented with local authorities, which for political, financial or practical reasons, fail to submit either an AQAP or subsequent progress reports, or, if they do submit a report, fail to implement any of the proposed measures. While it would be unjust to penalise local authorities whose inability to adhere to the timescales and reporting burden is beyond their control, e.g. in cases where the AQAP has become subjugated to the LTP reporting timeframes, the powerlessness of Defra to hold wilfully failing local authorities to account undermines the action planning process and diminishes the political weight that is, or should be, given to air quality remediation. The Localism Act 2011 has now introduced the possibility that fines for failing to meet EU Limit Values will be passed to local authorities [21]. Whether this risk of fiscal redress will raise the profile of air quality management in local authorities sufficient to prioritise AQAP measures remains to be seen, particularly given the financial burden already imposed by the Comprehensive Spending Review, the removal of many transport initiative funds and the reduction in air quality grants from Defra.

\subsubsection{The locus of local responsibility}

"Developing practicable action plans to deliver improvements in air quality will require firm commitment, collaboration, consultation and above all effective communication" [6].

As part of the LAQM process, environmental health departments normally have responsibility for producing the AQAP and for reporting on its progress. However, Environmental Health Officers (EHOs) are not in a position to be able to implement the types of measures that are required to address the sources that they have identified as causing exceedences. Such sources may range from a single unregulated industrial process to a busy urban motorway, or more usually a complex combination of multiple sources. Management of these sources will therefore be dependent on a number of other stakeholders and will be subject to existing policies at local, regional or national levels, well beyond the remit of the 
EHO. The ability of the EHO to engage with multiple internal and external stakeholders is dependent on mutual alignment of goals. While air quality is not the primary focus for land-use planners, for instance, the implications of their policies can have major repercussions for the generation of air quality issues, through the granting of planning applications that may introduce new sources or new exposure. Although air quality must be regarded as a material consideration in planning decisions (PPS 23), this must not be to the exclusion of all development and in practice there are very few planning refusals made on the grounds of air quality. Likewise, transport planners often have scant reference to air quality in their policy documents, but are crucial to the successful implementation of most AQAP measures. This misalignment of roles and responsibilities is perhaps one of the key reasons for the failure of action plan implementation. EHOs do not have the power to enforce cooperation and air quality is not seen as a priority by those that have the means to implement solutions.

\subsection{Opportunities for reconceptualisation}

The premise behind LAQM at its introduction in the late 1990s was that air quality would not be the widespread issue that has transpired. With the majority of local authorities in the UK now having exceedences of objectives for trafficrelated pollutants and with improvements difficult to implement, it is time to radically rethink the position of air quality management. At present air quality management is often seen as ancillary to established local government responsibilities and as a relatively new policy field faces stiff competition for resources and political support from other local priorities. Access to good quality air however is a fundamental right, comparable with access to clean water. Ensuring that the population are not exposed to potentially health-damaging pollution should therefore be a national priority. Furthermore, as there is no safe level of particulate matter $\left(\mathrm{PM}_{2.5}\right)$ [22], the pursuit of nominal 'health-based' objectives is perhaps pointless. Local authorities, rather than having to demonstrate that they have an air quality problem before seeking to resolve it, should assume that as default air quality improvement should be integral to all policy areas as part of a sustainable approach to the development of their area of jurisdiction. Likewise, national government should support this initiative through policy directives and funding which seek to consider air quality within this wider context. The obvious problem that this idealistic scenario faces is the departmental silos which currently exist in government and serve to undermine the implementation of AQAPs. A major restructuring of local and probably central government would be required in order to centralise sustainability as an underpinning ethos in local and national government into which all other departments contribute. Funding of measures to improve air quality should be borne by source following the 'polluter pays' principle. To apply this to traffic pollution would mean that the cost of driving petrol and diesel vehicles should include the externalised health burden of the resulting emissions. Given uncertainties over the precise health effects of air pollution and their associated costs this is not easily quantified, however a proportion of the health service 
costs could in theory be set by the government and charged to motorists through taxation. Fuel prices in the UK are already significantly inflated by duty and vehicle taxes are weighted in favour of lower $\mathrm{CO}_{2}$ emissions. Unfortunately the favourable taxes for diesel vehicles due to their fuel efficiency has been disadvantageous for local air quality [23], though low taxes on hybrid and alternatively fuelled vehicles is gradually encouraging uptake of these vehicles. Generally the use of vehicle taxes to encourage uptake of newer, cleaner vehicles is beneficial for air quality, though there is little evidence to suggest that the true cost of emissions is reflected in the vehicle tax charged, especially for older, more polluting vehicles.

\section{Conclusion}

This paper has highlighted some of the barriers to air quality action planning in the UK and has concluded that the root cause of these inefficiencies is due to flawed subsidiarity and the devolution of responsibility decoupled from the attendant powers required to implement. A lack of a legal requirement undermines the limited power that local authorities have to implement air quality management policies and inherent departmental silos serve to act as barriers to responsibility. Opportunities for reconceptualising LAQM and in particular action planning have been suggested, but they will require a major change in policy and a politically unacceptable restructuring of local and central government's approach to air quality.

\section{References}

[1] Brimblecombe, P. The Big Smoke, London: Routledge, 1987.

[2] Great Britain. The Air Quality Regulations 1997 3043. London. Available from: http://www.legislation.gov.uk/uksi/1997/3043/made, 1997.

[3] Department of the Environment, The United Kingdom National Air Quality Strategy. London: DoE, 1997.

[4] Department for the Environment, Transport and the Regions, The Air Quality Strategy for England, Scotland, Wales and Northern Ireland. London: DETR, 2000.

[5] DETR. Department for Transport, Road Traffic Statistics - Annual Road Traffic Estimates 2010 . London: National Statistics, 2012.

[6] NSCA, Interim Guidance on Air Quality Action Plans, 2000.

[7] NSCA, Air Quality: Planning for Action, 2001.

[8] Defra, Evaluation of Local Authority Air Quality Action Planning through Local Air Quality Management. Report number: CS/AQ/AD102126/RM/2131(Final).London: Casella Stanger, 2004.

[9] Defra, Evaluation of Support Provided by Defra and the Devolved Administrations to Local Authorities for Air Quality Action Planning through Local Air Quality Management. London: Defra, 2007.

[10] In House Policy Consultants, Review of Local Air Quality Management: A Report to Defra and the Devolved Administrations. IHPC, 2010. 
[11] Defra, Questionnaire Survey of UK Local Authorities on the Local Air Quality Management Process. Bristol: University of the West of England and Air Quality Consultants Ltd, 2009.

[12] House of Commons Environmental Audit Committee, Air Quality: Fifth Report of Session 2009-10. London: The Stationery Office Ltd, 2010.

[13] House of Commons Environmental Audit Committee, Air Quality: A FollowUp Report, Ninth Report of Session 2010-12. London: The Stationery Office Ltd, 2011.

[14] Beattie, C.I., Chatterton, T.J., Hayes, E., Leksmono, N., Longhurst, J.W.S. and Woodfield, N.K., Air Quality Action Plans in the UK: an overview and evaluation of process and practice, C.A. Brebbia and J.W.S. Longhurst, eds. In: Air Pollution XIV, 2006, WIT Press pp503-512, 2006.

[15] Olowoporoku, D., Hayes, E., Longhurst, J. and Parkhurst, G., The rhetoric and realities of integrating air quality into the local transport planning process in English local authorities. Journal of Environmental Management [online]. 101 (0), pp. 23-32, 2012.

[16] Chatterton, T.J., Hayes, E.T. and Longhurst, J.W.S., Managing air quality - are we doing enough? C.A. Brebbia and J.W.S. Longhurst, eds. In: Air Pollution $X I V$, 2006, WIT Press pp155-164, 2006.

[17] Olowoporoku, A. O., Hayes, E. T., Longhurst, J. W. S. and Parkhurst, G., Improving road transport-related air quality in England through joint working between Environmental Health Officers and Transport Planners. Local Environment 16 (3) 603-618, 2011.

[18] Beattie, C.I. The Impact of the Implementation of the Environment Act 1995, Part IV (Air Quality) on the Air Quality Management Practices of Urban Local Authorities in England, University of the West of England, 2003.

[19] Carslaw, D.C., Beevers, S.D., Tate, J.E., Westmoreland, E.J. and Williams, M.L. Recent evidence concerning higher NOx emissions from passenger cars and light duty vehicles. Atmospheric Environment [online]. 45 (39), pp. 7053-7063, 2011.

[20] Defra, Air Quality Plans for the Achievement of EU Nitrogen Dioxide (NO2) Limit Values in the UK: UK Overview Document. London: The Stationery Office, 2011.

[21] UK Government. Localism Act 2011 London, 2011.

[22] COMEAP, Long term exposure to air pollution: effect on mortality, 2009.

[23] Rhys-Tyler, G.A., Legassick, W. and Bell, M.C. The significance of vehicle emissions standards for levels of exhaust pollution from light vehicles in an urban area. Atmospheric Environment [online]. 45 (19), pp. 3286-3293, 2011. 